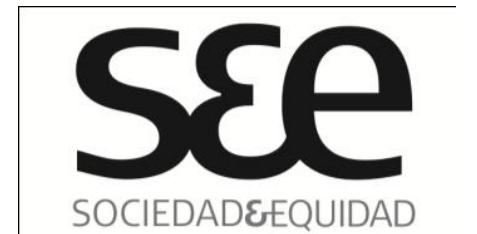

\title{
Producción generizada de los cuerpos en el discurso jurídico argentino. Análisis de tres fallos correspondientes al período $1970-2010^{(1)}$
}

Production of gendered bodies in the Argentine legal discourse. Analysis of three rulings during the period of $1970-2010$

$\begin{array}{ll}\text { Nombre: } & \text { Anahí Farji Neer }{ }^{(2)} \\ \text { Filiación: } & \text { Universidad de Buenos Aires UBA/ } \\ & \text { CONICET } \\ \text { País: } & \text { Argentina } \\ \text { Correo: } & \text { anahifarji@hotmail.com }\end{array}$

\section{RESUMEN}

Este trabajo se propone analizar la producción y regulación social de las corporalidades en las sociedades contemporáneas a través del discurso jurídico. Se analizan tres fallos producidos por el poder judicial argentino entre los años 1970 y 2010 que procesan solicitudes para la realización de cirugías de reasignación genital y cambio de nombre y sexo en el documento de identidad de personas cuyas corporalidades desafían la normatividad de género. El análisis indaga en torno a los cambios y continuidades en los marcos epistémicos disponibles para la lectura de los cuerpos-otros en el discurso jurídico y profundiza en las características de los esquemas actualmente vigentes. Del trabajo se desprende que a través del análisis de la regulación de los cuerpos y las sexualidades es posible visualizar los mecanismos a través de los cuales se define tanto lo humano como los ideales de ciudadanía históricamente configurados.

\section{ABSTRACT}

This paper analyzes how bodies in contemporary societies are produced and socially regulated through legal discourses. Three rulings produced by the Argentine Justice Department between 1970 and 2010 are analyzed. These rulings constitute requests

\footnotetext{
${ }^{1}$ El presente artículo forma parte de la Tesis de Maestría de la autora.

${ }^{2}$ La autora es Licenciada en Sociología por la Universidad de Buenos Aires. Sus líneas de investigación son en género y sexualidades.
} 


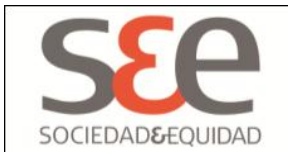

for genital reassignment surgery, change of name and sex in legal registers, petitions made by people whose corporalities defy the dominant gender rules. The analysis aims to trace changes and continuities in the epistemic frames available for reading the other bodies crystallized in legal discourse, as well as to inquire the characteristics of the current ways of thinking. The essay shows that through the analysis of the regulation of bodies and sexualities it is possible to visualize mechanisms through which we define what is considered human, and how ideals of citizenship are historically configured.

PALABRAS CLAVES: Discurso jurídico, corporalidad, travestismo, transexualidad, transgeneridad.

KEY WORDS: Legal discourse, corporality, travestism, transexualism ,transgenderism. 


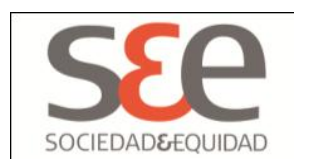

\section{Introducción}

Con el objetivo de analizar la producción y regulación social de las corporalidades en las sociedades contemporáneas, el presente trabajo se propone abordar las formas a través de las cuales el discurso jurídico opera como uno de los sistemas de representación normativa de los cuerpos. Para ello se analizarán tres fallos producidos por el poder judicial argentino entre los años 1970 y 2010 en los cuales se procesan solicitudes para la realización de cirugías de reasignación genital, así como para el cambio de nombre y sexo en el documento de identidad de personas cuyas corporalidades desafían la normatividad de género dominante basada en la linealidad de la tríada sexo-género-deseo ${ }^{3}$. Los mismos son analizados como acontecimientos representativos de una dinámica de cambios en las formas de regulación estatal del travestismo, la transexualidad y la transgeneridad ${ }^{4}$ en Argentina. El primer caso a analizar se trata de un pedido de autorización para la realización de una cirugía de reasignación genital feminizante del año 1974. Los dos restantes, producidos en los años 2007 y 2010 respectivamente, refieren a solicitudes de cambio de nombre y sexo registral.

El interés por realizar este análisis se encuentra dado por el hecho de que a partir de la última reapertura democrática argentina, gran parte del espectro de organizaciones sexo-políticas ${ }^{5}$ locales han definido como estrategia principal la demanda de derechos al Estado (Meccia, 2006; Moreno, 2008). En los últimos treinta años el discurso jurídico se ha conformado como un espacio de disputa por el reconocimiento de los cuerpos-otros como cuerpos legítimos. De este modo, la regulación biopolítica de los cuerpos se ha articulado como un proceso en que el cuerpo se ubica como locus de la acción política. Dicha dinámica iniciada por el feminismo a nivel mundial y local en la década de los ' 70 , adquiere en la actualidad un carácter particular dado por el contenido específico de las demandas de estas organizaciones y por el hecho de desplegarse de cara a las instituciones de la democracia (neo)liberal. Cabe entonces realizar este análisis a fin de rastrear cambios y continuidades en los marcos epistémicos disponibles para la lectura de los

\footnotetext{
${ }^{3}$ Siguiendo a Judith Butler, rige en nuestras sociedades un "modelo discursivo/epistemológico hegemónico de inteligibilidad del género, el cual supone que para que los cuerpos sean coherentes y tengan sentido debe haber un sexo estable expresado mediante un género estable (masculino expresa hombre, femenino expresa mujer) que se define históricamente y por oposición mediante la práctica obligatoria de la heterosexualidad” (Butler, 2001a: 38).

${ }^{4}$ Entendidas, en principio, como posiciones de sujeto que escapan de los patrones de inteligibilidad hegemónicos del binarismo genérico y la heterosexualidad obligatoria.

${ }^{5}$ Nos referimos a aquellas agrupaciones que se organizan con el fin de denunciar y revertir la invisibilización, discriminación y estigmatización a la que distintos sujetos identificados como gays, lesbianas, bisexuales, travestis, transexuales o transgénero -cuyas prácticas y deseos se distancian de la norma heterosexual dominante- se enfrentan cotidianamente.
} 


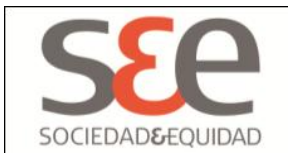

cuerpos-otros cristalizados en el discurso jurídico, así como para analizar las características de los esquemas sostenidos actualmente a fin de indagar en qué aspectos estos se diferencian radicalmente, o no, respecto de los anteriores.

Las preguntas que atraviesan el trabajo son las siguientes: ¿Cuáles son las características del discurso jurídico que hacen de este un discurso con operatividad y productividad social? ¿Cómo son leídos esos cuerpos-otros en la trama del discurso jurídico en cada uno de estos posicionamientos? ¿Cuáles son los discursos invocados para realizar dichas lecturas? ¿Qué cambios y continuidades pueden observarse entre estos tres hechos de producción y regulación jurídica de los cuerpos generizados?

\section{Breves reflexiones en torno al vínculo entre discurso jurídico y orden social}

Resulta pertinente para el análisis propuesto comenzar con una reflexión en torno a la forma en la que opera el discurso jurídico en nuestras sociedades, su funcionalidad social y su vinculación con el establecimiento de un orden genérico-normativo de los cuerpos. Para ello se retomarán desarrollos teóricos que han profundizado en dicho análisis desde una perspectiva crítica.

En principio, es posible afirmar que el discurso jurídico circula a través de normas, reglamentos, decretos, fallos, edictos y sentencias con la función de establecer lo permitido y lo prohibido formalmente en una sociedad. Es un tipo de discurso que al tiempo que prescribe, describe, esto es, dice algo sobre cómo debería ser el mundo y cómo es. Su pretensión de ser una descripción realista del mundo es una de las características que asume este tipo particular de discurso (Entelman, 1982). El sentido y la validez del mismo no están dados exclusivamente por la lógica que encadena sus enunciados sino también, y fundamentalmente, por la lógica de las prácticas en las que dicho discurso se inscribe. A fin de desarrollar esta idea, retomaremos la diferenciación foucaultiana entre lenguaje y discurso. Desde esta perspectiva, el lenguaje es un "conjunto de hechos lingüísticos ligados entre sí por reglas sintácticas de construcción" mientras que los discursos son las "reglas del juego a partir de las cuales vemos nacer ciertas formas de subjetividad, dominios de objeto y tipos de saber" (Foucault, 2009:13-17). Los discursos poseen dos dimensiones de significación -la interna y la externa- con sus propias reglas de constitución y exclusión, esto es, las reglas de lo que puede y no puede enunciarse (Foucault, 1987). Desde el punto de vista de la dimensión interna, el sentido está dado por el encadenamiento sistemático y coherente de sus enunciados y sus reglas internas de formación. En el caso del discurso jurídico, estas reglas refieren a los tipos de enunciados admitidos, los sujetos autorizados para producir e interpretar la norma, así como las formas rituales de distribución de la palabra y las condiciones necesarias para que ciertas palabras tengan validez jurídica (Entelman, 1982). La 


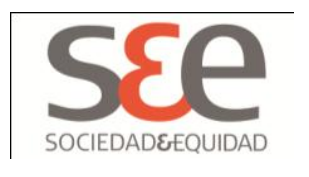

dimensión externa refiere a la forma en que ese discurso circula socialmente y los efectos operativos en la constitución de un campo de objetos y de unas subjetividades particulares (Entelman, 1982; Foucault, 1987).

Tomando en cuenta tanto la dimensión interna como la externa, en el caso particular del discurso jurídico, su operatividad está dada por su inscripción estatal, siendo esta la fuente de su autoridad. Su poder performativo -en el sentido de configurar sujetos y realidades jurídicas a través del propio acto enunciativo (Austin, 1988)- también proviene del rol que ocupa la institución estatal en nuestras sociedades. De este modo, resulta pertinente concebir a la institución judicial como una de las que "conforman el aparato en el que se condensa el poder y los recursos de la dominación política" (Oszlak, 1978: 8), obteniendo su legitimidad y poder productivo en base a dicho orden de dominación institucional; por ello se encuentra investido de los ropajes del discurso justo y de verdad. Según Ricardo Entelman, la "búsqueda de justicia impuesta al discurso jurídico funciona como ideal de verdad (...) provocando silencios en el discurso allí donde la certeza es indemostrable" (Entelman, 1982: 90). No obstante, no obtiene su legitimidad exclusivamente del poder institucional, sino también del orden cultural que lo sustenta: "El establecimiento de prohibiciones (es) una función central del discurso mismo. Pero las prohibiciones a las que aludimos no lo son necesariamente en el sentido técnico de prohibición jurídica, sino que aluden a ciertas amenazas vigentes en la cultura" (Entelman, 1982: 89).

Discurso jurídico y orden social se retroalimentan, ya que aquel opera también como dispositivo de legitimación y sostén del reparto desigual del poder en la sociedad, ofreciendo los mecanismos de obediencia y control social necesarios para la reproducción de un orden social jerárquico y desigualmente organizado. Enrique Marí (1994) agrega que para que sea operativo, el discurso del orden debe tener la capacidad de interpelar la emotividad de los sujetos, la movilización de creencias y sentimientos. Esta doble valencia del discurso jurídico es conceptualizada por Entelman como el "carácter mito-lógico de la racionalidad jurídica". Para aclarar esta idea, cabe retomar a Jacques Derrida (1992), para quien el fundamento último de la justeza y la fuerza de la ley no es más que ella misma, su propio carácter de ley y la violencia performativa que dicho carácter esconde; en ello radica su naturaleza mítica:

"La operación que consiste en fundar, inaugurar, justificar el derecho, hacer la ley, consistiría en un golpe de fuerza, en una violencia performativa y por tanto interpretativa, que no es justa o injusta en sí misma, y que ninguna justicia ni ningún derecho previo y anteriormente fundante, ninguna fundación preexistente, podría garantizar, contradecir o invalidar por definición” (Derrida, 1992: 139). 


\section{SEe}

La emotividad que el discurso jurídico invoca obedece también al hecho de que al nombrar y especificar a los individuos, los constituye como sujetos que se hacen inteligibles a través de las categorías que este ofrece. En este sentido, Judith Butler establece que "el sujeto se forma a través de la búsqueda apasionada del reconocimiento amonestador del Estado" (Butler, 2001b: 143).

Por todo ello resulta importante reflexionar sobre la forma en la que este discurso se imbrica con el orden normativo de los cuerpos y los géneros. Al respecto cabe señalar que el discurso jurídico opera en base a una idea pretendidamente abstracta de ciudadano equiparándolo a un sujeto heterosexual masculino (Maffía, 2001; Moreno, 2002; Pateman, 1995). Promueve así una idea universal de lo humano a imagen y semejanza de dicho modelo. Asimismo, naturaliza un concepto particular de sexualidad haciéndolo inteligible exclusivamente en términos dicotómicos y lineales entre sexo-género-deseo. Entendiendo estos conceptos en términos binarios y dicotómicos, la noción de "sexo" refiere a la existencia de cuerpos sexuados en tanto machos o hembras, el "género" al hecho de adscribir a la identidad femenina o masculina y la idea de "deseo" u "orientación sexual" se establece teniendo en cuenta el género de las personas ubicadas como objeto de amor y/o placer ${ }^{6}$ que se espera, en base a la matriz heterosexual dominante, que sean del sexo/género opuesto. El discurso jurídico opera entonces como un dispositivo que produce sujetos generizados a la luz de dicha idea.

En este sentido cabe pensar, acorde a lo desarrollado por Judith Butler en "Vida precaria" (2006b), que existe una "noción normativa de lo que debe ser un cuerpo humano" (2006b: 59). Fuera de dicha normatividad, basada en aspectos tanto sexuales y genéricos como raciales, existen vidas que no se encuentran protegidas por el derecho por no adecuarse a lo que cuenta como una vida que valga la pena. Toda experiencia que queda por fuera de este esquema pasa a ser un fenómeno particular y atípico, generando tensiones entre lo pretendidamente universal y lo particular, lo público y lo privado, binomios que son impuestos por el mismo discurso. De allí que la característica de los fallos que se analizarán a continuación refieren a decisiones judiciales sobre aquello que no está regulado -como es la solicitud de cambio de sexo registral- y sobre aquello que está ambiguamente definido en las leyes -como el caso del "justo motivo" necesario para solicitar el cambio de nombre- De este modo, el discurso jurídico funciona como un ámbito en el que es posible negociar la definición de la frontera culturalmente establecida entre los cuerpos legítimos y los ilegítimos (Rubin, 1989), así como los límites de aquello que puede

\footnotetext{
${ }^{6}$ En el caso de aquellas personas identificadas como travestis, transexuales y/o transgénero, dicha linealidad y binariedad queda subvertida por la adopción de una identidad genérica contraria a lo dictaminado por este esquema basado en una lectura dicotómica de la genitalidad de los cuerpos.
} 


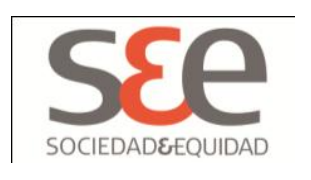

definirse culturalmente como humano. Teniendo en cuenta que el cuerpo posee una dimensión marcadamente pública y se constituye entonces como un fenómeno social, los reclamos por el cambio de sexo y nombre registral de aquellas personas cuyos cuerpos desafían la línealidad entre cuerpo-género-deseo representan mucho más que el pedido por ejercer un derecho individual; conllevan la disputa por hacer inteligibles unas formas de estar en el mundo que desafían los patrones hegemónicos de corporalidad.

\section{El discurso jurídico y la regulación de los cuerpos-otros: análisis de tres fallos correspondientes al período 1970-2010}

A continuación se analizarán los tres fallos judiciales ya mencionados. Serán abordados como casos representativos de distintas formas en las que el campo jurídico en Argentina produce y regula las corporalidades-otras del travestismo, la transexualidad y la transgeneridad. A través de su análisis se retomarán las preguntas planteadas. Interesa en particular describir y analizar el contenido de los mensajes presentes en estos fallos, teniendo en cuenta que los mismos no pueden escindirse de sus condiciones de producción y recepción.

En el año 1965 fue presentada por primera vez una solicitud de cambio de sexo y nombre registral en Argentina, obteniendo una respuesta negativa. Dado que el mismo no fue publicado y por ello no es posible acceder a este, se analizará el segundo fallo encontrado, producido en el año 1974 por un Juzgado Civil de la Capital Federal. En el mismo se solicita autorización para la realización de una operación de reasignación genital feminizante. Dicho pedido fue también negado, entendiendo la intervención solicitada como una operación "mutiladora" prohibida por ley y alegando que el "desequilibrio psicológico" de la persona que lo solicitaba ameritaba no dar curso a su pedido.

En lo que refiere a su estructura interna, el fallo comienza mencionando el marco legal comprometido en el pedido (la Ley de Ejercicio de la Medicina y el Código Penal); luego presenta las pruebas producidas por los peritos médicopsiquiátricos ("examen morfológico", “determinación cromosómica” y "examen psicológico"). En base al diagnóstico obtenido en dichas pruebas, define a la persona que solicita la intervención quirúrgica -a la que siempre refiere en forma masculinacomo "sujeto psíquicamente desequilibrado y de conformación morfológica perfectamente masculina". Asimismo, destaca que el "enfoque paranoico del sujeto y la posibilidad de que, dado el monto de su heteroagresividad, puede llegar a revestir peligrosidad". Continúa luego caracterizando el origen de dicho padecimiento y establece que "sus angustias y sus inclinaciones por el travestismo y sus peculiaridades de conducta que lo sitúan en el transexualismo tienen origen en desviaciones eminentemente psicológicas". De este modo, especifica al sujeto dentro del fenómeno del transexualismo entendido como una "desviación de la tendencia 


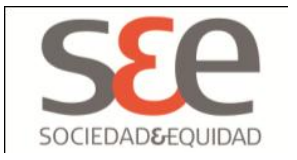

sexual" y sub-especie del "trastorno homosexual". En lo que refiere al rol que ocupan las pericias médicas, cabe retomar a Michel Foucault (2000) en su análisis sobre el entrecruzamiento del discurso médico y judicial. Este establece que las pericias médico-legales extraen su poder de una doble fuente: de la institución judicial con la autoridad pública que de ella emana, y de la institución médica que le otorga el status de verdad y cientificidad. En dicho marco, los efectos de verdad de las pericias médico legales obedecen al status de quien las enuncia, más que a su contenido.

Finalmente, el fallo explicita los motivos por los cuales la sentencia es negativa. Refiere así a la tensión entre "los derechos del individuo humano para resolver respecto a una intervención mutiladora sobre su propio cuerpo" y "el alcance de los derechos de la sociedad a oponerse a que el individuo disponga libremente de su cuerpo". Luego argumenta que "la operación quirúrgica cuya autorización se solicita no transferiría la libido del paciente a su ubicación normal". Remite entonces al discurso psicoanalítico al hacer uso del concepto de "libido", definiendo no obstante cuáles serían los objetos "normales" y cuáles los "desviados" para depositar dicha energía. Esta característica promovería entonces "su tendencia, puesta de manifiesto por los estudios de psicodiagnóstico, a estructurar su personalidad con mayor predominio del funcionamiento paranoide (...) lo que acrecentaría el peligro que corre de caer en autodestrucción". Especifica de este modo la subjetividad de la persona solicitante bajo los términos de la enfermedad y la peligrosidad.

Cabe hacer mención entonces a algunas ideas expuestas en este fallo que revisten especial importancia para su análisis. Por un lado, se encuentra presente la idea de un sexo natural y verdadero que es develado por las pericias médicas y que debe ser resguardado jurídicamente, así como el carácter desviado y peligroso de la persona que solicita autorización judicial para realizarse una operación que adecue su apariencia física a la forma en la que se identifica genéricamente. Asimismo, comprende este deseo dentro de la gramática del fenómeno homosexual. De este modo, la "homosexualidad" cifra toda una gama inespecífica de actos y deseos que desafían la norma heterosexual, entendiéndola como una desviación patológica de la que no deben tolerarse sus intentos de engaño o desafío a las leyes naturales.

Encontramos que la negativa al pedido se basa en la necesidad de ejercer una doble tutela: sobre los derechos de la sociedad a oponerse a que el individuo disponga libremente de su cuerpo y sobre la vida de la persona, quien realizaría dicho pedido en el marco de un desequilibrio psíquico. La presunta peligrosidad que revisten los sujetos cuyos cuerpos y deseos se desvían de la norma heterosexual radica no solo en que estos deseos acarrearían un riesgo para sus propias vidas -ya que por tratarse de seres enfermos carecerían de autonomía y capacidad de autocuidado-, sino también, y sobre todo, en que su accionar representaría un acto 


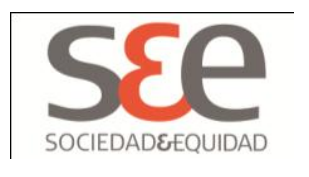

fraudulento contra la naturaleza y contra el orden institucional, moral y social que la institución judicial debe sostener.

Ha de tenerse en cuenta que el contenido de dicho fallo responde a un marco político y cultural que habilita dicha forma de regulación. Las implicancias para el orden social de regular y controlar las sexualidades y los cuerpos pueden rastrearse desde los idearios fundacionales de la nación argentina de la llamada "generación de '80". En palabras de Pablo Ben: "la consolidación del Estado Nacional no puede ser comprendida sin un análisis de las imposiciones que desde allí se realizaron para adecuar las subjetividades a un modo representado por el varón blanco heterosexual, occidental, argentino y de elite" (Ben, 2000: 64). La autoridad pública y el saber médico se han imbricado mutuamente en lo que refiere a las definiciones de la normalidad y la anormalidad. Los pares de oposiciones civilización-barbarie, salubreinsalubre, fueron los que delinearon las fronteras modelizadas de ciudadanía. La figura del "enemigo" equiparada a una enfermedad que amenazaría la integridad de todo el cuerpo-nación, fue una de las principales características del pensamiento higienista que influenció las políticas locales de control social a partir de esa época. Al decir de Jorge Salessi “distintas construcciones y formas de representación de las desviaciones sexuales sirvieron a distintos propósitos” (1995: 179). Así, el control, la estigmatización y la criminalización de aquellos deseos y prácticas que se distancian de la forma marital de sexualidad con fines reproductivos, sirvió para forjar y delimitar el ideal de ciudadano argentino en formación y, conjuntamente con la pobreza y la subversión, para demarcar una frontera de aceptabilidad social (Ben, 2000; Guy, 1994). A dicho ideario que signó los orígenes del pensamiento político argentino se sumó, a partir de fines de los años sesenta y hasta la reapertura democrática de 1983, la preocupación de los gobiernos locales por la caída demográfica, entendiendo que las necesidades geopolíticas y los proyectos de desarrollo se vinculaban directamente con el tamaño de la población. Estos intereses promovieron una serie de políticas públicas que tuvieron como eje del control a aquellos sujetos cuyas prácticas escindieran el placer sexual de la reproducción. Ello fomentó políticas natalistas y de defensa de la moral y las buenas costumbres a fin de controlar y criminalizar aquellas prácticas identificadas con el fenómeno homosexual (Felitti, 2006). El fallo recién analizado puede entonces identificarse con dichos idearios e intereses.

El segundo fallo seleccionado fue producido en el año 2007 por la Corte Suprema de Justicia de la Provincia de Buenos Aires y se trata de un pedido de autorización de cambio de nombre y sexo registral de "masculino" a "femenino" de una persona que se había realizado previamente una cirugía de reasignación genital feminizante. Dicho pedido fue autorizado $y$, si bien no fue el primer caso con 


\section{Sse}

sentencia favorable ${ }^{7}$, ha sido seleccionado teniendo en cuenta la legitimidad y autoridad que emana de una Corte Suprema.

En este fallo se explicitan los 3 votos de los Jueces de la Corte que de forma unánime revocan una sentencia anterior por parte de un Tribunal de Familia. Aquel había priorizado la "inalterabilidad del sexo cromosómico" por sobre la identidad sentida, alegando que esta no habilitaba a autorizar el cambio registral.

Comienza presentando la solicitud y al igual que el caso anterior, refiere a la normativa en juego: la "Ley del Nombre" y la Ley de "Registro del estado civil y capacidad de las personas". Acto seguido presenta las pericias medico-psicológicas en base a las cuales concluye que se trata de una persona de "caracteres morfológicamente femeninos, con constitución genética masculina (...) sin que se hayan detectado anomalías estructurales" y que la "configuración psíquica de su sexualidad (se) corresponde a una mujer". Destaca el hecho de que la existencia previa de una cirugía de reasignación genital delimita el campo del debate, otorgando especial importancia jurídica a la morfología genital. En consonancia con los resultados de dichas pericias, define los factores que componen el diagnóstico de transexualismo según la Clasificación Internacional de las Enfermedades de la Organización Mundial de la Salud (CIE 10 $)^{8}$, considerando que la persona se adecuaría fielmente a dicho trastorno.

Cabe destacar que ya no se entiende este pedido como parte del fenómeno homosexual, sino dentro de una taxonomía médico-psiquiátrica específica. En continuidad con el fallo anterior, el reconocimiento público de las corporalidades no normativas es cifrado no solo en los términos jurisprudenciales (ya que el pedido debe adecuarse al lenguaje y ordenamiento lógico del discurso jurídico), sino también en los términos de un diagnóstico médico. A fin de ser leídas como parte de lo posible dependen, en última instancia, de su adecuación a dicho diagnóstico. Retomando a Foucault, "la pericia permite pasar del acto a la conducta, del delito a la manera de ser" (Foucault, 2000: 29). De este modo, todas las acciones llevadas a cabo por los sujetos que encarnan la "transexualidad" son englobadas, entendidas y explicadas por dicha categoría.

\footnotetext{
${ }^{7}$ El primer fallo con sentencia favorable a un pedido de similares características fue emitido por un Juzgado Civil y Comercial de Quilmes en el año 1997.

8 “1) Identificación de un modo intenso y persistente con el otro sexo; 2) malestar permanente con el sexo asignado (disforia de género); 3) ausencia de los padecimientos físicos o psíquicos de los llamados estados intersexuales; 4) pruebas de malestar clínicamente significativo o deterioro social, laboral o de otras áreas del individuo". Cabe tener en cuenta que el diagnóstico "transexualismo" fue incorporado al DSM-III (clasificación de trastornos mentales de uso generalizado entre psiquiatras de todo el mundo) en el año 1980. El mismo diagnóstico fue incorporado al C.I.E. 10 del año 1992 aún vigente. En la reforma del DSM-IV del año 1994 se sustituyó dicho término por el de "trastorno de identidad de género".
} 


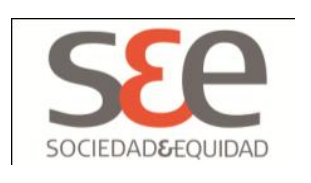

Luego de desarrollar la definición del transexualismo, presenta una concepción multidimensional de sexo como fundamento para otorgar el pedido solicitado. A diferencia del fallo inicial que entiende a la sexualidad en forma monádica, esta noción incluye sendas dimensiones: lo cromosómico, lo gonádico, lo hormonal, lo genital externo, lo anatómico (o caracteres sexuales secundarios) y lo psicológico. Asimismo, entiende que esta última dimensión puede disociarse de las restantes.

El dictamen favorable se basa en la valoración de la intimidad y la dimensión de lo privado, ámbito en el que entiende que radica la vivencia de la sexualidad y el uso del cuerpo. No obstante, hace explícito que dicho derecho se otorga bajo ciertos límites, esto es, en tanto y cuanto no comprometa la convivencia $a^{9}$ o el bien común: "La identidad sexual de C., que pertenece - sin duda- a la esfera de su mayor intimidad, en tanto no se exteriorice de una forma que pudiera afectar la convivencia social ni perturbe el bien común, no es de las acciones que interesan al orden jurídico".

A diferencia del fallo anterior, este es producto de un marco institucional democrático que sostiene el respeto y la no injerencia estatal en las acciones privadas de las personas y en el que los principios de no discriminación han sido incorporados al rango constitucional. De este modo, el Estado tolera aquello que preferiría que no existiera y permite su existencia a costa de conminarlo a la esfera de lo privado. Cabe retomar entonces el análisis que realiza Ernesto Meccia en torno a la noción de tolerancia y a la división estatal entre público y privado, ya que para el autor "la configuración del Estado (y los órdenes de lo público y lo privado que inaugura) están hechos a imagen y semejanza de las necesidades del imperativo heterosexual con todas las subordinaciones de género que conlleva" por lo tanto, "la tolerancia no tiene razón de ser si previamente su objeto no fue definido de modo adverso" (Meccia, 2006: 79). Lejos de debatir el esquema binario de género imperante, el reconocimiento estatal a la identificación femenina asumida por quien realiza este pedido se presenta como un caso excepcional y la acción del Estado representa un paliativo para el sufrimiento de una persona que necesitaría acercarse artificialmente a aquello que desea más nunca llegará a ser:

Las intervenciones que modificaron su morfología genital exterior (...) brinda(n) alivio al tormento (...) al obtener, ante sí y a los ojos de los otros, la correspondencia de la imagen corporal deseada y el sexo sentido y vivido. A

\footnotetext{
${ }^{9}$ Esta idea respecto al vínculo entre los usos del cuerpo y la convivencia urbana, remite claramente a los debates en torno a la sanción del código contravencional de la Ciudad Autónoma de Buenos Aires y sus sucesivas modificaciones a partir del año 1998, en el que se puso en entredicho la relación entre género y sexualidad en torno al uso del espacio público. Sobre este punto se recomienda ver Sabsay (2011) y Delfino y Salomón (2003).
} 


\section{Sse}

través de tales prácticas médicas se borran -amputan- los atributos genitales vergonzantes y rechazados, para remplazarlos por un símil de los que tipifican el sexo opuesto.

Siguiendo a Judith Butler, el diagnóstico del trastorno de la identidad de género "ofrece un cierto discurso de compasión (...) que sugiere que la vida con este tipo de trastornos causa angustia e infelicidad" (Butler, 2006: 145). Esta forma de entender el pedido en términos de tormento o sufrimiento fue abordada por Mauro Cabral en su comentario a un fallo producido en el año $2008^{10}$. El mismo allí afirma que "la identidad de género se vuelve una noción relevante en términos jurídiconormativos solo cuando se combina, dramáticamente, con un cuerpo incapaz de encarnarla (...) sin remitir jamás a un escenario más amplio de exclusión, discriminación y opresión estructural, el fallo termina por naturalizar ese drama" (2008).

Finalmente, se dispone a otorgar la "ficción jurídica" de un sexo registral distinto al sexo biológico, con la salvedad de que en los casos "en los que ignorar el sexo genético lesione el orden público", la identidad real de la persona debería informarse de forma tal de asegurar el "derecho de los demás a no ser engañados". Esto es, en caso de matrimonio, adopción o competencia deportiva. En conclusión, se otorga aquí el reconocimiento público a la identidad genérica reclamada entendiendo dicho reconocimiento como un caso excepcional en un marco de tolerancia de lo no deseado pero inevitable, y como paliativo al sufrimiento expresado por quien es víctima de una patología. Sin dejar de lado el aparente dilema entre lo real y el artificio o imitación, concibe al sexo genético como la dimensión que en última instancia debe resguardarse jurídicamente para proteger el interés del Estado o de terceros, aún pretendiendo adoptar una noción de sexo multidimensional.

Al igual que en el fallo anterior, se encuentra puesta en cuestión la capacidad de los sujetos de disponer de su propio cuerpo en lo que refiere a su uso, transformación y manipulación en oposición a las normas de género dominante y la traducción de dicha posibilidad en el plano legal. Siguiendo a Roberto Esposito (2009) podemos afirmar que el gran eje problemático que articula dicha tensión es el proceso que en las sociedades modernas ha llevado a la cosificación del cuerpo. Dicha cosificación se encuentra presente tanto en los esquemas biopolíticos como en el paradigma de los Derechos Humanos que -articulando lo que el autor denomina "dispositivo de la persona" (Esposito, 2009)- se planteó como objetivo impedir que se vuelva a perpetuar un régimen biotanatopolítico como fue el nazismo. No obstante la pretendida oposición entre ambos esquemas, estos comparten la escisión cuerpo-

${ }^{10}$ Se trata de un fallo producido en el año 2008 en la Ciudad de Mar del Plata en el que la cirugía de reasignación genital no fue solicitada como condición para otorgar el cambio registral de sexo y nombre (Cabral, 2008). 


\section{SEe}

razón, cuerpo-mente, privilegiando en el esquema de los Derechos Humanos la dimensión racional y desestimando la corpórea. En tanto seres humanos con una doble valencia racional-animal, solo adquieren estatus de personas quienes dominan plenamente la dimensión corporal bajo cierta definición normativa de lo humano, al tiempo que la posibilidad de ser plenos sujetos de derechos está dada siempre que se encarne dicha categoría. El dispositivo genera entonces sus propios mecanismos de exclusión al establecer una gradación que va de las personas plenas a las antipersonas en virtud de cuánto dominan su dimensión animal-corporal o cuánto se encuentran dominados por ella ${ }^{11}$. En base a dichos planteamientos, el fenómeno de la cosificación del cuerpo es lo que podría explicar el hecho de que aun en un contexto de plena vigencia del paradigma de los Derechos Humanos y promoviendo el respeto al fuero íntimo de la persona, se reclame en última instancia el resguardo jurídico del sexo genético en tanto sustrato último de lo que es entendido como verdad corporal. Por otro lado, a través de dichos mecanismos podemos visualizar la especificación de una categoría particular de persona bajo el diagnóstico de la transexualidad como medio para acceder a un derecho específico, aunque ello se asiente en aquel dispositivo que cosifica los cuerpos.

El último fallo a analizar, producido en el año 2010 por parte de un Juzgado en lo Contencioso, Administrativo y Tributario de la Ciudad de Buenos Aires, se trata de un pedido de cambio de nombre y sexo registral de "masculino" a "femenino" de una persona que no presenta ni solicita la realización de una cirugía de reasignación genital.

En principio el juez expone el caso tal como el mismo fue elevado por la demandante, en el que incluye un relato de vida manifestando que "desde muy temprana edad sintió un deseo irrefrenable de vestirse y relacionarse conforme el sexo femenino". En base al pedido, el juez afirma la importancia para el orden público de la inmutabilidad del nombre. No obstante ello, explicita que existe posibilidad legal de modificarlo, no siendo este el caso para el cambio de sexo registral. Destaca que en los casos en los que este tipo de pedidos han sido autorizados judicialmente siempre han contado con el requisito de la cirugía de reasignación genital. A fin de evaluar lo solicitado, se dispone a diferenciar la noción de sexo respecto de la de género, explicitando que "se entiende por 'género' al conjunto de pautas culturales y sociales que se utilizan para distinguir las actitudes o conductas que socialmente se consideran masculinas o femeninas". Luego se establece que

11 “Gradación o degradación entre persona plena, semipersona, no-persona y antipersona, representadas respectivamente por el adulto, el infante, o el viejo desvalido, el enfermo irrecuperable y el loco" (Esposito, 2009: 26). 


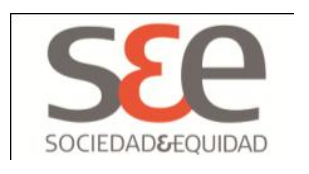

Tradicionalmente, el sexo de una persona es fijado en el momento de su nacimiento, circunstancia que determina su registro dentro de las categorías convencionales de 'hombre' y 'mujer'. Sin embargo, ocurre que este hecho puede resultar altamente conflictivo para un porcentaje de individuos. Este grupo está compuesto (...) por personas cuya autopercepción innata difiere de la percepción que su entorno tiene de ellas y en base a la cual se las registró al momento de su nacimiento.

Cabe mencionar este pasaje en particular, dado que aquí el juez no recurre a categorías médicas, ni tampoco reduce el problema a un caso aislado. Por el contrario, lo entiende como una experiencia común a un grupo de personas ya que nada determina necesariamente la identidad de género que los sujetos habrán de adoptar. No obstante, reconoce que estas múltiples posibilidades identificatorias no tienen posibilidad de ser formalmente reconocidas por los mecanismos estatales vigentes. En esa misma línea argumental sostiene que las mismas "no constituyen 'perversiones', 'desviaciones', 'sujetos sexualmente inclasificables' o 'errores de la naturaleza'”. Se afirma así una noción pluralista y no patologizante respecto de las identidades genéricas que escapan del binarismo genérico, sostenida por parte de un operador jurídico.

Este cambio en el posicionamiento estatal se encuentra dado en parte por un proceso de instalación en la agenda pública del problema de la vulneración sistemática de derechos de las personas cuyas identidades y deseos se distancian de la heterosexualidad obligatoria, promovido por las organizaciones sexo-políticas desde la década de 1990. El debate y sanción de la "Ley de matrimonio igualitario" en el año 2010 fue fruto de dicho proceso y generó un clima de apertura hacia la recepción estatal de otras demandas vinculadas a los derechos sexuales, como es el caso de la respuesta estatal analizada.

Si bien en este caso no se recurre a pericias médicas ni establece como requisito la cirugía de reasignación genital, sí se establece como condición la estabilidad, persistencia y reconocimiento por parte de los otros del género que se pretende validar legalmente. Una existencia acorde a los patrones sociales del género reclamado, en condiciones estables y contando con la posibilidad de acreditar dicha estabilidad por parte de otras personas, son las condiciones impuestas en este caso para obtener el reconocimiento estatal. Poseen entonces valor de pruebas jurídicas las declaraciones de los/as testigos presentados por la solicitante quienes afirmaron que 


\section{sfe \\ SOCIEDADEEQUIDAD}

desde que conocen a la actora siempre la han visto con aspecto y comportamiento femenino $(\mathrm{y})$ destacaron los múltiples inconvenientes y padecimientos que le produce la circunstancia de no poder contar con documentación que refleje su identidad de género y el nombre femenino por el que es conocida y con el cual interactúa en sociedad.

Es así que el juez puede afirmar que "la actora posee una identidad femenina, que exterioriza en su aspecto y en el nombre por el que es conocida e interactúa socialmente (...) y que tal circunstancia se presenta de modo estable y persistente". Su “identidad femenina”, entonces, es corroborada por el juez, aun sin establecer cuáles son los contenidos o las condiciones que permiten establecer dicha afirmación, dado que ello le haría incurrir en los mismos estereotipos de los cuales busca desprenderse. En consonancia con el fallo anteriormente analizado, el fundamento de su resolución positiva está basado en la protección de la intimidad y los aspectos privados de la personalidad. No obstante, incorpora el principio de autonomía personal y la valoración de los propios planes de vida, absteniéndose de considerarla como una persona enferma cuya existencia deba ser tutelada.

La tensión entre interés individual e interés colectivo continúa atravesando la exposición argumental, aunque en este caso se considera que la protección de los intereses individuales se encuentran incluidos en el interés colectivo, dado que ello tendería a promover la inclusión social de la totalidad de los integrantes del colectivo social más allá de la diversidad de deseos y corporalidades que estos posean. No obstante, cabe retomar a Leticia Sabsay, para quien la protección y celebración de la diversidad por la diversidad misma, "se limita a clasificar una cantidad de identidades discretas (...) cooptadas por una idea implícita de universalidad que clausura la 'diferencia' y la limita a lo que esa noción universal de 'diversidad' prevé como aceptable" (Sabsay, 2011: 75). De este modo, el reconocimiento otorgado bajo la bandera de la protección de la diversidad, corre el riesgo de dejar fuera de discusión los mecanismos que hacen que algunas identidades tengan que llegar a la instancia de solicitarle al Estado que las reconozca como humanas mientras que otras son definidas como tales de por sí.

Cabe destacar que el hecho de reconocer el derecho a la identidad como parte del fuero íntimo, privado y personal se basa no solo en la división liberal de lo público y lo privado -a la que ya nos hemos referido en el análisis del caso anteriorsino que también se sustenta en una idea de sujeto que al decir de Sabsay, debe ser "capaz de realizar demandas de derechos sobre la base del establecimiento de fronteras que estabilizan su identidad" (Sabsay, 2011: 78). Es un sujeto que para devenir sujeto político y de derechos precisa ser autónomo, autoconsciente y autocentrado, con una identidad estable. Ello se ve reflejado en el requisito de la 


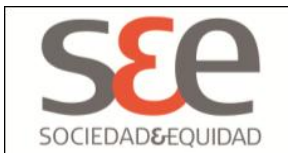

estabilidad y persistencia en el género autoatribuido. El juez reconoce el género de la persona solicitante sustentando una idea voluntarista y emprendedora de la propia identidad, que remite asimismo a una noción (neo)liberal de la identidad, esto es, "como una empresa o una autoproducción" (Sabsay, 2011:75). Estas concepciones dejan de lado el hecho de que las nociones de autonomía o autoproducción conllevan un dilema, ya que no es posible pensar un sujeto que tome sus decisiones escindido de los marcos históricos de relaciones de poder-saber que lo producen como tal.

De cualquier modo, cabe preguntarse si el hecho de vivir en cierto modo acorde al género masculino o femenino, en ninguno de ellos, o en una permanente transición entre ambos, responde a una decisión independiente y voluntaria de cualquier persona o si más bien demuestra la imposibilidad de encarnar plenamente los géneros binarios hegemónicamente construidos. No obstante, el requisito jurídico para ser cifradas como identidades posibles sigue siendo la correcta encarnación de los géneros hegemónicamente instituidos.

\section{Reflexiones finales}

A través del análisis de los tres fallos presentados nos propusimos abordar las formas mediante las cuales el discurso jurídico lee y regula las corporalidades que desafían el binarismo genérico. Comenzamos analizando la relación entre discurso jurídico y orden social, considerando que el discurso jurídico opera como dispositivo de legitimación y sostén del reparto desigual del poder al ofrecer los mecanismos de obediencia y control social necesarios para la reproducción de un orden social jerárquicamente organizado. Es un discurso que posee la capacidad de interpelar la emotividad de los sujetos, movilizar sus creencias y sentimientos, así como nombrarlos y especificarlos a través de las categorías que ofrece. El discurso jurídico es también un lenguaje en disputa por su doble valencia de locus de discurso legitimado y de legitimación. Por todo ello, se consideró necesario reflexionar sobre la forma en la que este discurso configura y regula las corporalidades en términos genéricos, ya que el mismo funciona como un ámbito en el que se disputa la definición de la frontera culturalmente establecida entre los cuerpos legítimos y los ilegítimos y los límites de aquello que puede definirse como humano.

Tras analizar tres fallos en los que se dirime el estatus jurídico de las corporalidades que desafían el binarismo de género en distintos momentos históricos, fue posible visualizar ciertas tensiones que vale la pena destacar. En líneas generales, los tres fallos comparten una estructura interna común en la que se presenta el pedido, la normativa implicada en el caso, las pruebas para su resolución, la posición del juez en base a sus definiciones de los conceptos en juego y finalmente la decisión judicial. En los tres casos se encuentra presente una tensión entre el orden público -que requiere la inmutabilidad del nombre y sexo registral- y el interés del individuo -ya sea para disponer de su cuerpo interviniéndolo, como 


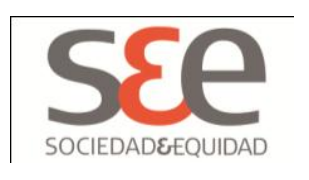

para solicitar su cambio de identificación legal-. Asimismo, se encuentra en cuestión la capacidad de los sujetos de disponer de su propio cuerpo y la traducción de dicha posibilidad en el plano legal, lo que lleva a pensar en los procesos de cosificación del cuerpo en las sociedades contemporáneas.

En los dos primeros fallos se invocan como pruebas judiciales los peritajes médicos que se encargan de indagar en la morfología genital, el sexo genético y la identidad psicológica de la persona. Se destacó que las pericias médico-legales extraen su poder de una doble fuente: de la institución judicial con la autoridad pública que de ella emana y de la institución médica que le otorga su estatus de verdad y cientificidad. En la estructura de estos fallos las pericias operan produciendo una verdad: ya sea la verdad del sexo que debe resguardarse legalmente (en el primer fallo se trata del sexo genético masculino), como la verdad en términos de diagnóstico (en el segundo fallo se trata del diagnóstico de transexualismo). Esa verdad es la que permitirá a los jueces exponer una resolución pretendidamente justa. En el caso del segundo fallo particularmente, el reconocimiento público de las corporalidades no normativas es cifrado en los términos del diagnóstico psiquiátrico del transexualismo. A fin de ser leídas como parte de lo posible y como destinatarias de un derecho específico, dependen de su adecuación a dicho diagnóstico. En el último fallo analizado no se usó como prueba a la pericia psiquiátrica; por el contrario, este se fundamentó en aquellos testimonios que daban cuenta de una correcta encarnación de la identidad de género femenina que la persona solicitante reclamaba.

En base a los casos analizados es posible afirmar que las experiencias corporales que desafían el binarismo de género solo pueden ser cifradas por el discurso jurídico, ya sea a través del fenómeno inespecífico de la desviación de la tendencia sexual, de un diagnóstico médico, o bien de la adecuación estable y ajustada a lo que socialmente es reconocido como lo masculino o lo femenino.

En lo que respecta a los conceptos jurídicos resguardados en cada fallo, el rechazo en el primer caso analizado, un fallo producido en el año 1974, se orientaba a tutelar los derechos de la sociedad y la vida del individuo, ya que como persona enferma se encontraría imposibilitada de ejercer una acción autónoma y de disponer libremente de su cuerpo. En el caso del fallo del año 2007, el dictamen favorable se basó en la preservación de la intimidad de la persona, siendo la vida privada una dimensión sobre la cual Estado no debe inmiscuirse. De este modo, se pone de manifiesto que el Estado conmina el tratamiento de la pluralidad de sexualidades y corporalidades a la esfera de lo privado en términos de casos atípicos y excepcionales. En el tercer fallo analizado el juez entendió el reclamo como una experiencia común a un grupo de personas, afirmando así una noción pluralista y no patologizante. No obstante, solicitó pruebas que dieran cuenta de la estabilidad y persistencia dentro del género requerido, al tiempo que evaluó su correcto 


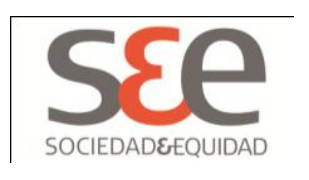

desempeño en base a los parámetros estereotípicos de dicho género. Luego, el fallo positivo se fundamentó en el principio de autonomía personal acorde a una idea voluntarista y emprendedora de la identidad, soslayando el hecho de que no es posible pensar en un sujeto que tome decisiones por fuera de los marcos históricos y sociales que lo producen como tal. Las categorías dicotómicas de género que el discurso jurídico instituye permanecen así inmutables e indiscutidas.

Consideramos que la regulación de los cuerpos y las sexualidades no es un tema que atañe exclusivamente a la vida privada de las personas, sino que es un fenómeno que debe ser abordado desde la óptica de la dinámica política. En este sentido, es posible afirmar que los cambios en el tratamiento judicial de estos cuerpos-otros responden a distintos intereses políticos presentes en cada caso y a la correlación de fuerzas que se establece entre los movimientos sexo-políticos y el Estado en cada momento particular. Los argumentos denegatorios de lo solicitado en el primer fallo pueden ser entendidos como una forma de resguardo frente una forma de vida que es entendida como una amenaza a cierta definición normativa de lo humano y al ideal de ciudadanía históricamente configurado. En el momento en que dicho fallo fue producido aún no se encontraban legitimadas socialmente concepciones que discutieran dichos argumentos. Por el contrario, tanto el segundo como el tercer fallo analizado se produjeron en contextos democráticos en los que las organizaciones sexo-políticas habían logrado articular una visión contrapuesta a esas concepciones y se habían ubicado como actores demandantes de políticas públicas al Estado. En particular, la emergencia del virus del SIDA en la década del ' 80 permitió instalar a nivel internacional la temática de la vulneración de derechos de las personas no heterosexuales. En el contexto local, el trabajo de las organizaciones sexo-políticas ante la enfermedad les permitió conformarse como interlocutores válidos frente al Estado ${ }^{12}$. Asimismo, la vinculación de dicha vulneración de derechos con la problemática de los Derechos Humanos, instalada luego de la última dictadura militar, habilitó un cambio en el discurso social vigente respecto de las formas de vida que desafían la heterosexualidad obligatoria y el binarismo de género. El proceso de articulación con distintos actores sociales -tales como partidos políticos y organismos de Derechos Humanos- sostenido a lo largo del tiempo y la consecuente acumulación de capital social, permitió instalar el debate público respecto del estatus legal de las parejas del mismo sexo, que culminó con la modificación de la Ley de Matrimonio en el año 2010. En particular, las agrupaciones de travestis, transexuales y transgénero a partir de la década del '90 habían iniciado un proceso de organización y articulación de sus reivindicaciones frente al Estado ${ }^{13}$. Si bien la consigna más fuerte giraba en torno a la descriminalización de sus identidades -la derogación de los Edictos Policiales en la Ciudad de Buenos Aires en

\footnotetext{
${ }^{12}$ Para profundizar sobre este punto se recomienda ver Pecheny (2000).

${ }^{13}$ Para mayor profundidad sobre este punto ver Berkins (2003).
} 


\section{s\&e \\ SOCIEDADEEQUIDAD}

el año 1998 representó un hito en este sentido-, también apuntaron al cambio en los significantes a través de los cuales sus demandas eran otorgadas, particularmente todos aquellos sentidos que las asociaran a formas de vida enfermas o patológicas.

Todo ello redunda en una dinámica histórica en la que las organizaciones lograron ubicarse como actores legítimos en distintos espacios -tanto estatales como no estatales- e impulsaron el ingreso de sus demandas en la agenda pública. En definitiva, al ubicarse como interlocutores de importancia frente al Estado y la sociedad en general, las organizaciones promovieron un paulatino cambio en las representaciones culturales afirmando sus formas de vida como viables y legítimas, proceso que queda plasmado en el contenido de los documentos analizados en el presente trabajo.

\section{Referencias Bibliográficas}

Althusser, L. (1988). Ideología y aparatos ideológicos de Estado. Freud y Lacan. Buenos Aires: Nueva Visión.

Austin, J. (1988). Cómo hacer las cosas con palabras. Palabras y acciones. Barcelona: Paidós.

Ben, P. (2000). Muéstrame tus genitales y te diré quién eres. El hermafroditismo en la Argentina finisecular y de principios del siglo XX. En Barrancos, D. Cuerpos, géneros e identidades: estudios de historia de género en Argentina (pp. 62-104). Buenos Aires: Ediciones del Signo.

Berkins, L. (2003). “Un itinerario político del travestismo”. En Maffía, D. (comp.): Sexualidades Migrantes. Género y Transgénero (pp. 127-137). Buenos Aires: Feminaria.

Butler, J. (2006a). Desdiagnosticar el género. En Deshacer el género (pp.113-149). Barcelona: Paidós.

Butler, J. (2006b). Vida precaria. El poder del duelo y la violencia. Buenos Aires: Paidós.

Butler, J. (2001a). El género en disputa. Barcelona: Paidós.

Butler, J. (2001b). Mecanismos psíquicos del poder. Teorías sobre la sujeción. Madrid: Ediciones Cátedra. 


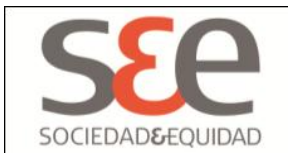

Cabral, M. (2008) Comparecer. Un comentario. [en línea]. [consulta: 20 de Agosto 2011]. Recuperado en <http://www.artemisanoticias.com.ar/site/notas.asp?id=51\&idnota=6287>

Delfino, S. y Salomón G. (2003). "Regulaciones culturales y luchas políticas: el caso del Código Contravencional de la Ciudad de Buenos Aires". Revista Jurídica de la Universidad Interamericana de Puerto Rico. Septiembre - Diciembre, 151-168.

Derrida, J. (1992). Fuerza de ley: el fundamento místico de la autoridad. Revista Doxa. 11, 129-191.

Entelman, R. (1982). Aportes a la formación de una epistemología jurídica en base a algunos análisis del funcionamiento del discurso. En VVAA. El discurso jurídico. Perspectiva psicoanalítica y otros abordajes epistemológicos (pp. 85-109). Buenos Aires: Hachette.

Espósito, R. (2009). Tercera persona. Política de la vida y filosofía de lo impersonal. Buenos Aires: Amorrortu.

Felitti, K. (2006). En defensa de la libertad sexual: discursos y acciones feministas y homosexuales en los 70s. Revista Temas de mujeres. Revista del CEHIM, CEHIM - UNT Año 2. 2, 44-64.

Foucault, M. (2009). La verdad y las formas jurídicas. Barcelona: Gedisa.

Foucault, M. (2000). Los anormales. Buenos Aires: Fondo de Cultura Económica.

Foucault, M. (1990). Historia de la sexualidad. Buenos Aires: Siglo XXI.

Foucault, M. (1987). El orden del discurso. Barcelona: Tusquets.

Guy, D. (1994). El sexo peligroso. La prostitución legal en Buenos Aires. Buenos Aires: Ed. Sudamericana.

Maffia, D. (2001). Ciudadanía sexual. Aspectos personales, legales y políticos de los derechos reproductivos como derechos humanos. Revista Feminaria Año XIV. 26-27, 28-30.

Marí, E. (2002). La Teoría de las Ficciones. Buenos Aires: Eudeba. 


\section{SEe}

Marí, E. (1996). Papeles de filosofía 2 (...para arrojar al alba): La teoría de las ficciones en la política y la filosofía. Buenos Aires: Biblos.

Marí, E. (1994). Derecho y psicoanálisis. Teoría de las ficciones y ficción dogmática. Buenos Aires: Edicial.

Marí, E. (1986). "Racionalidad e imaginario social en el discurso del orden. Revista Doxa. Cuadernos de Filosofía del Derecho. 3, 93-112.

Meccia, E. (2006). La cuestión gay. Un enfoque sociológico. Buenos Aires: Gran Aldea Editores.

Moreno, M. A. (2001). Políticas sociales, ciudadanía y corporalidad: vínculos y tensiones. Revista Feminaria. 28/29, 16-24.

Pateman, C. (1995). El contrato sexual. Barcelona: Anthropos/Universidad Autónoma Metropolitana.

Pecheny, M. (2000). La salud como vector del reconocimiento de derechos humanos: la epidemia de SIDA y el reconocimiento de los derechos de las minorías sexuales. En Ana Domínguez Mon et al. La salud en crisis. Un análisis desde la perspectiva de las ciencias sociales. Buenos Aires: Ed. Dunken.

Rubin, G. (1989). Reflexionando sobre el sexo: notas para una teoría radical de la sexualidad. En Vance, C. (comp.) Placer y peligro. Explorando la sexualidad femenina. Madrid: Editorial Revolución.

Sabsay, L. (2011). Fronteras sexuales: espacio urbano, cuerpos y ciudadanía. Buenos Aires: Paidós.

Salessi, J. (1995). Médicos maleantes y maricas. Higiene, criminología y homosexualidad en la construcción de la nación argentina (1871-1914). Rosario: Beatriz Viterbo Editora.

\section{Documentos}

“Autorización judicial - improcedencia- $1^{\circ}$ Instancia Civil Capital firme, juzgado $\mathrm{N}^{\circ}$ 14, septiembre 24-974 - NN". 


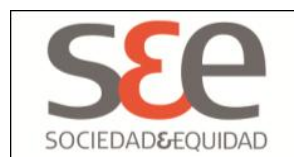

"Suprema Corte de Justicia de la Provincia de Buenos Aires, 21/03/2007 - C.H.C.".

"Juzgado 1ra Instancia en lo Contencioso Administrativo y Tributario de la Ciudad Autónoma de Buenos Aires, 29/12/2010 - P.M.". 